\title{
Investigation of Salmonella Enteritidis outbreaks in South Africa using multi-locus variable-number tandem-repeats analysis, 2013-2015
}

Munyadziwa Muvhali ${ }^{1,2^{*}}$, Anthony Marius Smith ${ }^{1,2}$, Andronica Moipone Rakgantso ${ }^{3}$ and Karen Helena Keddy ${ }^{1,2}$

\begin{abstract}
Background: Salmonella enterica serovar Enteritidis (Salmonella Enteritidis) has become a significant pathogen in South Africa, and the need for improved molecular surveillance of this pathogen has become important. Over the years, multi-locus variable-number tandem-repeats analysis (MLVA) has become a valuable molecular subtyping technique for Salmonella, particularly for highly homogenic serotypes such as Salmonella Enteritidis. This study describes the use of MLVA in the molecular epidemiological investigation of outbreak isolates in South Africa.

Methods: Between the years 2013 and 2015, the Centre for Enteric Diseases (CED) received 39 Salmonella Enteritidis isolates from seven foodborne illness outbreaks, which occurred in six provinces. MLVA was performed on all isolates.

Results: Three MLVA profiles (MLVA profiles 21, 22 and 28) were identified among the 39 isolates. MLVA profile 28 accounted for $77 \%$ (30/39) of the isolates. Isolates from a single outbreak were grouped into a single MLVA profile. A minimum spanning tree (MST) created from the MLVA data showed a close relationship between MLVA profiles 21, 22 and 28, with a single VNTR locus difference between them.

Conclusions: MLVA has proven to be a reliable method for the molecular epidemiological investigation of Salmonella Enteritidis outbreaks in South Africa. These foodborne outbreaks emphasize the importance of the One Health approach as an essential component for combating the spread of zoonotic pathogens such as Salmonella Enteritidis.
\end{abstract}

Keywords: Non-typhoidal Salmonella (NTS), Salmonella Enteritidis, Multi-locus variable-number tandem-repeats analysis (MLVA), Variable-number tandem-repeat (VNTR), Salmonella outbreaks

\section{Background}

Salmonella is a major cause of morbidity and mortality in children under the age of five in most developing countries worldwide [1-3]. The global human health impact of nontyphoidal Salmonella (NTS) is high, with an estimated 93.8 million illnesses, of which 80.3 million are reported to be foodborne related, and 155,000 deaths each year [4]. Human illness caused by Salmonella

\footnotetext{
*Correspondence: mmuvhali@gmail.com

${ }^{1}$ Centre for Enteric Diseases, National Institute for Communicable Diseases, Johannesburg, South Africa

${ }^{2}$ Faculty of Health Sciences, University of the Witwatersrand, Johannesburg, South Africa

Full list of author information is available at the end of the article
}

enterica serovar Enteritidis (Salmonella Enteritidis) has drastically increased worldwide, and by the 1980's Salmonella Enteritidis had replaced Salmonella enterica serovar Typhimurium (Salmonella Typhimurium) as the primary cause of salmonellosis globally [5].

In developed countries, NTS usually causes selflimiting gastroenteritis with fewer numbers of deaths in humans compared to developing countries [6]. In Africa, NTS is commonly associated with invasive disease which leads to a high burden of morbidity and mortality [7-9]. In Africa, the burden of non-invasive Salmonella Enteritidis has not been established. However, it is estimated that Salmonella Enteritidis accounts for $33.1 \%$ of the 
total invasive NTS infections [10]. Despite global efforts to curb its spread Salmonella Enteritidis infections persist, causing an on-going challenge to the global health system.

In South Africa, laboratory-based surveillance of enteric bacteria for public health importance was initiated in 2003, by the Centre for Enteric Diseases (CED) at the National Institute for Communicable Diseases (NICD). The surveillance was mainly in response to the human immunodeficiency virus (HIV) epidemic in the country. During that period, the predominant invasive NTS serotypes were Salmonella Typhimurium and Salmonella enterica serovar Isangi $[6,11]$. The introduction of highly active antiretroviral therapy (HAART) in 2004 showed a gradual decline in invasive salmonellosis, more especially in those serotypes that were associated with HIV infection such as Salmonella Typhimurium, whose association with HIV in Africa has been extensively described [12]. Even so, Salmonella Typhimurium remained the most common cause of salmonellosis in South Africa. However, in 2011 Salmonella Enteritidis became more prevalent and overtook Salmonella Typhimurium as the most commonly identified Salmonella serotype, and the overall number of Salmonella Enteritidis cases reported to the CED have increased [13, 14]. This increase is still inexplicable and it is independent of the HIV epidemic in the country.

Pulsed-field gel electrophoresis (PFGE) is still commonly used for the molecular subtyping of Salmonella. However, it lacks good discriminatory power in genetically homogeneous serotypes such as Salmonella Enteritidis. In most instances, it is unable to successfully discriminate outbreak from non-outbreak strains and in such cases, successful discrimination is only attained through the combination of intensive epidemiological, genotypic and phenotypic methods [15-17].

Over the years, multi-locus variable-number tandemrepeats analysis (MLVA) has become a useful molecular subtyping technique for Salmonella and it has shown good discriminatory power between Salmonella Enteritidis strains $[17,18]$. This technique characterises strains based on size differences in amplified DNA fragments at various variable-number tandem-repeat (VNTR) loci regions, found in the genome of most bacterial species $[19,20]$.

Between the years 2013 and 2015, the CED received isolates from seven foodborne illness outbreaks, for further laboratory analysis. The outbreaks occurred within six provinces in South Africa namely; Gauteng (GA), Limpopo (LP), Mpumalanga (MP), Eastern Cape (EC), Free State (FS) and KwaZulu-Natal (KZN). In this paper, we describe the use of MLVA in the molecular investigation of isolates from these outbreaks.

\section{Methods}

Outbreaks and notification

A foodborne illness outbreak is defined as any food poisoning incident involving two or more individuals that are epidemiologically linked to a common food/beverage source. Foodborne outbreaks are reported to the Outbreak Response Unit (ORU) of the NICD, which provides technical support for outbreak investigation and control in South Africa. The ORU works in close association with the CED linking molecular data with epidemiological data from the outbreak investigation [21]. Between 2013 and 2015, seven suspected outbreaks were reported to ORU, in which NTS was the implicated pathogen.

Receiving and processing of outbreak isolates at the CED The CED serves as a reference centre for human enteric pathogens in South Africa, including those identified in outbreaks. During outbreak investigations, the CED receives suspected outbreak-associated isolates from food and environmental (public health) laboratories and the clinical diagnostics microbiology laboratory involved. Salmonella isolates from seven suspected outbreaks were sent to CED for further characterisation. Isolate identification was confirmed using the Vitek 260 system (bioMérieux, Durham, United States of America) and serotyping (White-Kauffman-Le Minor scheme) [22].

\section{Crude genomic DNA extraction from bacteria}

Crude DNA was extracted from a pure overnight culture of Salmonella Enteritidis by inoculating a small loopful of bacterial culture in autoclaved TE buffer $(10 \mathrm{mM}$ Tris, $1 \mathrm{mM}$ EDTA; pH 8.0) and boiling the suspension at $95{ }^{\circ} \mathrm{C}$ for $25 \mathrm{~min}(\mathrm{~min})$. The suspension was centrifuged at $13200 \mathrm{rpm}$ for $3 \mathrm{~min}$ to pellet the cellular debris and $20 \mu \mathrm{l}$ of the supernatant was diluted in $80 \mu \mathrm{l}$ of autoclaved TE buffer ( $\mathrm{pH}$ 8.0).

\section{MLVA}

A previously described MLVA technique containing five VNTR loci (SENTR7-SENTR5-SENTR6-SENTR4SE-3) for Salmonella Enteritidis was used in this study (Table 1) [15]. A multiplex PCR was performed to amplify the five VNTR loci regions. Each PCR run and subsequent MLVA analysis always included a negative control (reaction tube with no DNA added) and a positive control. The positive control included the analysis of a well-validated Salmonella Enteritidis isolate; this isolate was well validated previously and consistently showed a VNTR loci allele size pattern (123-292-184-112-306).

A Qiagen multiplex PCR kit (Qiagen, Hilden, Germany) was used for the PCR. Each $25 \mu \mathrm{l}$ reaction contained $12.5 \mu \mathrm{l}$ of the Qiagen master mix, $2.5 \mu \mathrm{l}$ 
Table 1 MLVA loci and PCR primer sequences

\begin{tabular}{|c|c|c|c|c|c|}
\hline Target gene locus & PCR primer & Primer sequence $\left(5^{\prime}\right.$ to $\left.3^{\prime}\right)$ & Expected fragment sizes (bp) & VNTR repeat length (bp) & VNTR references \\
\hline \multirow[t]{2}{*}{ SENTR7 } & SENTR7-F & 6FAM-ACGATCACCACGGTCACTTC & $117-135$ & 9 & [15] \\
\hline & SENTR7-R & CGGATAACAACAGGACGCTTC & & & \\
\hline \multirow[t]{2}{*}{ SENTR5 } & SENTR5-F & 6FAM-CACCGCACAATCAGTGGAAC & $235-301$ & 6 & {$[15]$} \\
\hline & SENTR5-R & GCGTTGAATATCGGCAGCATG & & & \\
\hline \multirow[t]{2}{*}{ SENTR6 } & SENTR6-F & NED-ATGGACGGAGGCGATAGAC & $173-236$ & 7 & {$[15]$} \\
\hline & SENTR6-R & AGCTTCACAATTTGCGTATTCG & & & \\
\hline \multirow[t]{2}{*}{ SENTR4 } & SENTR4-F & VIC-GACCAACACTCTATGAACCAATG & $112-147$ & 7 & [15] \\
\hline & SENTR4-R & ACCAGGCAACTATTCGCTATC & & & \\
\hline \multirow[t]{2}{*}{ SE-3 } & SE-3-F & VIC-CAACAAAACAACAGCAGCAT & $308-320$ & 12 & {$[15]$} \\
\hline & SE-3-R & GGGAAACGGTAATCAGAAAGT & & & \\
\hline
\end{tabular}

Qiagen Q-solution, $1 \mu \mathrm{M}$ of each fluorophore-labelled forward and reverse primer, and $50 \mathrm{ng}$ of DNA template ( $1 \mu \mathrm{l}$ of crude genomic DNA preparation). The PCR cycling conditions included: denaturation at $95{ }^{\circ} \mathrm{C}$ for $15 \mathrm{~min}$, followed by 35 cycles of $60 \mathrm{~s}(\mathrm{sec})$ at $94{ }^{\circ} \mathrm{C}, 90 \mathrm{~s}$ at $55{ }^{\circ} \mathrm{C}, 90 \mathrm{~s}$ at $72{ }^{\circ} \mathrm{C}$, and a final extension at $72{ }^{\circ} \mathrm{C}$ for $10 \mathrm{~min}$. The PCR amplicons were diluted 2:198 in PCR grade water and $1 \mu \mathrm{l}$ of the dilution was combined with $0.2 \mu \mathrm{l}$ of GeneScan 600 LIZ Standard v2.0 (Applied Biosystems, Foster City, USA) and $12 \mu \mathrm{l}$ of Hi-Di formamide (Life Technologies, Warrington, UK).

The fragment size of each VNTR locus was determined by capillary electrophoresis on the Applied Biosystems 3500 Genetic Analyzer (Applied Biosystems). Data was analysed using the GeneMapper Software version 4.1 (Applied Biosystems) and is briefly described as follows. The DNA fragments were automatically allocated to length bins and the VNTR loci alleles were assigned based on the bin fragment sizes. The VNTR loci allele sizes were captured into the BioNumerics Software version 6.5 (Applied Maths, Sint-MartensLatem, Belgium) as character values. The VNTR loci allele sizes were used to assign MLVA profile numbers. A single VNTR locus difference resulted in a new MLVA profile being defined (e.g. 123, 268, 184, 112, 318 MLVA profile 1 and 123, 262, 184, 112, 318_ MLVA profile 2). A dendrogram was constructed by the UPGMA method, using the categorical coefficient with a 0 tolerance and a minimum spanning tree (MST) was constructed using the MST categorical coefficient.

\section{Results}

\section{Isolates and outbreaks}

From 2013 to 2015, the CED received 39 isolates associated with seven reported foodborne illness outbreaks. A total of 38/39 (97\%) isolates (isolated from stool samples) were obtained from human cases. One isolate was obtained from each human case. Of the 39 isolates, 1/39 (3\%) isolate was obtained from a food sample. All 39 isolates from the seven outbreaks were confirmed to be Salmonella Enteritidis through serotyping.

\section{Outbreak 1}

Outbreak 1 occurred in the KZN province during May 2013. Two people became ill after consuming meat (the liver) from a goat that had died from illness. Three isolates were received (two human isolates and one goat meat isolate). The outbreak isolates were analysed with MLVA retrospectively and all the isolates belonged to MLVA profile 22 (Tables 2 and 3).

\section{Outbreak 2}

Outbreak 2 occurred in the MP province in November 2013. The outbreak was associated with food poisoning. However, no further details were provided about the outbreak. Three human isolates were received from the outbreak. The outbreak isolates were analysed with MLVA retrospectively and all the isolates belonged to MLVA profile 22 (Tables 2 and 3).

\section{Outbreak 3}

Outbreak 3 occurred in the LP province in January 2014. This foodborne outbreak occurred in a lodge. Sixty-five people were affected, eight of whom were admitted to hospital in critical condition. Three human isolates were received from the outbreak. The outbreak isolates were analysed with MLVA retrospectively and all the isolates belonged to MLVA profile 28 (Tables 2 and 3).

\section{Outbreak 4}

Outbreak 4 occurred in the MP province in July 2014. The outbreak was associated with food prepared for a funeral. Forty-six people were affected, six of whom were children who were admitted to hospital in critical condition. Fourteen human isolates were received from the outbreak. The outbreak isolates were analysed with MLVA retrospectively and all the isolates belonged to MLVA profile 28 (Tables 2 and 3). 
Table 2 Detailed summary of the seven Salmonella Enteritidis outbreaks

\begin{tabular}{|c|c|c|c|c|c|c|c|c|c|c|}
\hline Outbreak & Province $^{a}$ & $\begin{array}{l}\text { Outbreak } \\
\text { date }\end{array}$ & $\begin{array}{l}\text { No. of } \\
\text { cases }\end{array}$ & $\begin{array}{l}\text { No. of } \\
\text { patient } \\
\text { deaths }\end{array}$ & $\begin{array}{l}\text { No. of } \\
\text { patients } \\
\text { admitted }\end{array}$ & $\begin{array}{l}\text { Clinical samples } \\
\text { collected }\end{array}$ & $\begin{array}{l}\text { Food samples } \\
\text { tested }\end{array}$ & $\begin{array}{l}\text { Food } \\
\text { testing } \\
\text { results }\end{array}$ & $\begin{array}{l}\text { No. of isolates } \\
\text { tested at CED }\end{array}$ & $\begin{array}{l}\text { CED test } \\
\text { results }\end{array}$ \\
\hline 1 & KZN & May 2013 & 2 & 0 & 0 & Stool $(n=2)$ & $\begin{array}{l}\text { Goat meat } \\
(n=1)\end{array}$ & $\begin{array}{l}\text { Salmonella } \\
\text { Enteritidis }\end{array}$ & 3 & $\begin{array}{l}\text { Salmonella } \\
\text { Enteritidis }\end{array}$ \\
\hline 2 & MP & $\begin{array}{l}\text { November } \\
2013\end{array}$ & unknown & unknown & unknown & unknown & unknown & unknown & 3 & $\begin{array}{l}\text { Salmonella } \\
\text { Enteritidis }\end{array}$ \\
\hline 3 & $L P$ & $\begin{array}{l}\text { January } \\
2014\end{array}$ & 65 & 0 & 8 & Stool $(n=8)$ & $\begin{array}{l}\text { Chicken } \\
\text { ( } n=\text { unknown) }\end{array}$ & unknown & 3 & $\begin{array}{l}\text { Salmonella } \\
\text { Enteritidis }\end{array}$ \\
\hline 4 & MP & July 2014 & 46 & 0 & 6 & $\begin{array}{l}\text { Stool }(n=12) \\
\text { Rectal swabs }(n=2)\end{array}$ & unknown & unknown & 14 & $\begin{array}{l}\text { Salmonella } \\
\text { Enteritidis }\end{array}$ \\
\hline 5 & FS & $\begin{array}{l}\text { November } \\
2014\end{array}$ & 80 & unknown & 6 & unknown & unknown & unknown & 3 & $\begin{array}{l}\text { Salmonella } \\
\text { Enteritidis }\end{array}$ \\
\hline 6 & EC & $\begin{array}{l}\text { December } \\
2014\end{array}$ & unknown & unknown & unknown & unknown & unknown & unknown & 10 & $\begin{array}{l}\text { Salmonella } \\
\text { Enteritidis }\end{array}$ \\
\hline 7 & GA & $\begin{array}{l}\text { October } \\
2015\end{array}$ & 4 & 0 & 4 & Stool $(n=4)$ & unknown & unknown & 3 & $\begin{array}{l}\text { Salmonella } \\
\text { Enteritidis }\end{array}$ \\
\hline
\end{tabular}

Provinces $^{\mathrm{a}}$ : Gauteng (GA), Limpopo (LP), Mpumalanga (MP), Eastern Cape (EC), Free State (FS) and KwaZulu-Natal (KZN)

$n=$ total number

\section{Outbreak 5}

Outbreak 5 occurred in the FS province in November 2014. The outbreak was associated with food prepared for a function in a mine. Eighty people were affected, six of whom were hospitalized. Three human isolates were received from the outbreak. All isolates belonged to MLVA profile 28 (Tables 2 and 3).

\section{Outbreak 6}

Outbreak 6 occurred in the EC province in December 2014. The outbreak occurred in a TB hospital. However, no further details were provided about the outbreak. Ten human isolates were received from the outbreak. All isolates belonged to MLVA profile 28 (Tables 2 and 3).

\section{Outbreak 7}

Outbreak 7 occurred in the GA province in October 2015. The outbreak was in a private residence, where a mother had cooked chicken feet for dinner. Four children were affected (age 4, 7, 8 and 11). Three human isolates were received from the outbreak. All isolates belonged to MLVA profile 21 (Tables 2 and 3).

\section{MLVA data}

The seven outbreaks showed a total of three different MLVA profiles. All isolates within an outbreak always showed an identical MLVA profile (Fig. 1). MLVA profile 21 (123_274_184_112_318) was present in 3/39 (7.7\%) isolates; all the isolates were from outbreak 7 (GA). MLVA profile 22 (123_262_184_112_318) was present in 6/39 (15.3\%) isolates; three isolates from outbreak 1 (KZN) and three isolates from outbreak 2 (MP). MLVA profile 28 (123_268_184_112_318) accounted for 77\% (30/39) of the total outbreak isolates. This MLVA profile contained three isolates from outbreak 3 (LP), 14 isolates from outbreak 4 (MP), three isolates from outbreak 5 (FS) and 10 isolates from outbreak 6 (EC). Consequently, MLVA profile 28 was the most predominant MLVA profile, followed by MLVA profile 22 and 21 respectively.

\section{Discussion}

For many years, PFGE was considered the gold standard for subtyping of salmonellae. It was deemed a useful method for outbreak investigations in support of phage typing, when further strain discrimination was required.

Table 3 Summary of the outbreaks MLVA data

\begin{tabular}{llll}
\hline Outbreak & Province $^{a}$ & VNTR loci fragment sizes (SENTR7-SENTR5-SENTR6-SENTR4-SE-3) & MLVA profile \\
\hline Outbreak 1 & KZN & $123-262-184-112-318$ & 22 \\
Outbreak 2 & MP & $123-262-184-112-318$ & 22 \\
Outbreak 3 & LP & $123-268-184-112-318$ & 28 \\
Outbreak 4 & MP & $123-268-184-112-318$ & 28 \\
Outbreak 5 & FS & $123-268-184-112-318$ & 28 \\
Outbreak 6 & EC & $123-268-184-112-318$ & 28 \\
Outbreak 7 & GA & $123-274-184-112-318$ & 21
\end{tabular}

Province: Gauteng (GA), Limpopo (LP), Mpumalanga (MP), Eastern Cape (EC), Free State (FS) and KwaZulu-Natal (KZN) 


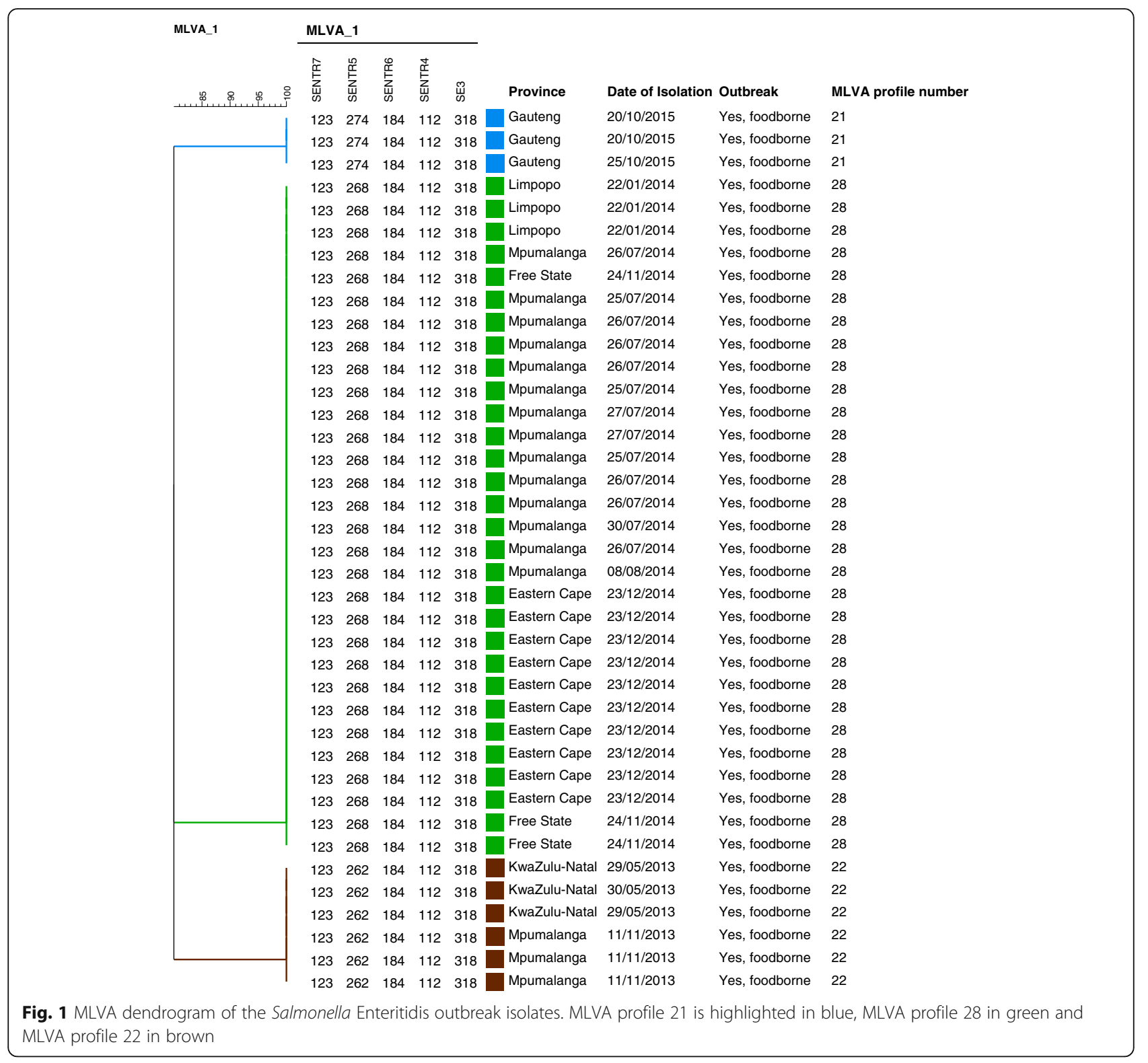

However, Salmonella Enteritidis has limited heterogeneity (lacks genetic variation), thus making discrimination beyond phage typing challenging [15]. The application of MLVA to a wide variety of bacterial species including Salmonella species showed that it was more discriminatory compared to other available molecular subtyping methods [17].

The CED currently does MLVA for Salmonella Enteritidis isolates from the GA and Western Cape (WC) Provinces. The analysis of the GA and WC Salmonella Enteritidis isolates using MLVA was initiated in 2013. The VNTR loci allele sizes obtained from these isolates were used to establish a Salmonella Enteritidis MLVA profile number database. In the established CED MLVA database, 84 MLVA profiles have been determined from
1221 human isolates, obtained from various body sites (manuscript in preparation-unpublished data). Of the 84 MLVA profiles, four notable MLVA profiles (MLVA profiles 28, 7, 22 and 21) have been identified (Fig. 2).

In this current study, MLVA profile 28 accounted for majority of the outbreaks (5/7 outbreaks), thus showing that it may be highly propagative within South Africa. Furthermore, MLVA profile 28 accounts for a large number of isolates in the established CED MLVA database. MLVA profiles 21 and 22 are also some of the common MLVA profiles in the CED MLVA database. Further analysis of the MST shows that MLVA profiles 21 and 22 are closely related to MLVA profile 28, with a single VNTR locus difference between them (Fig. 2). This difference was observed in VNTR locus SENTR5. High variation (high 


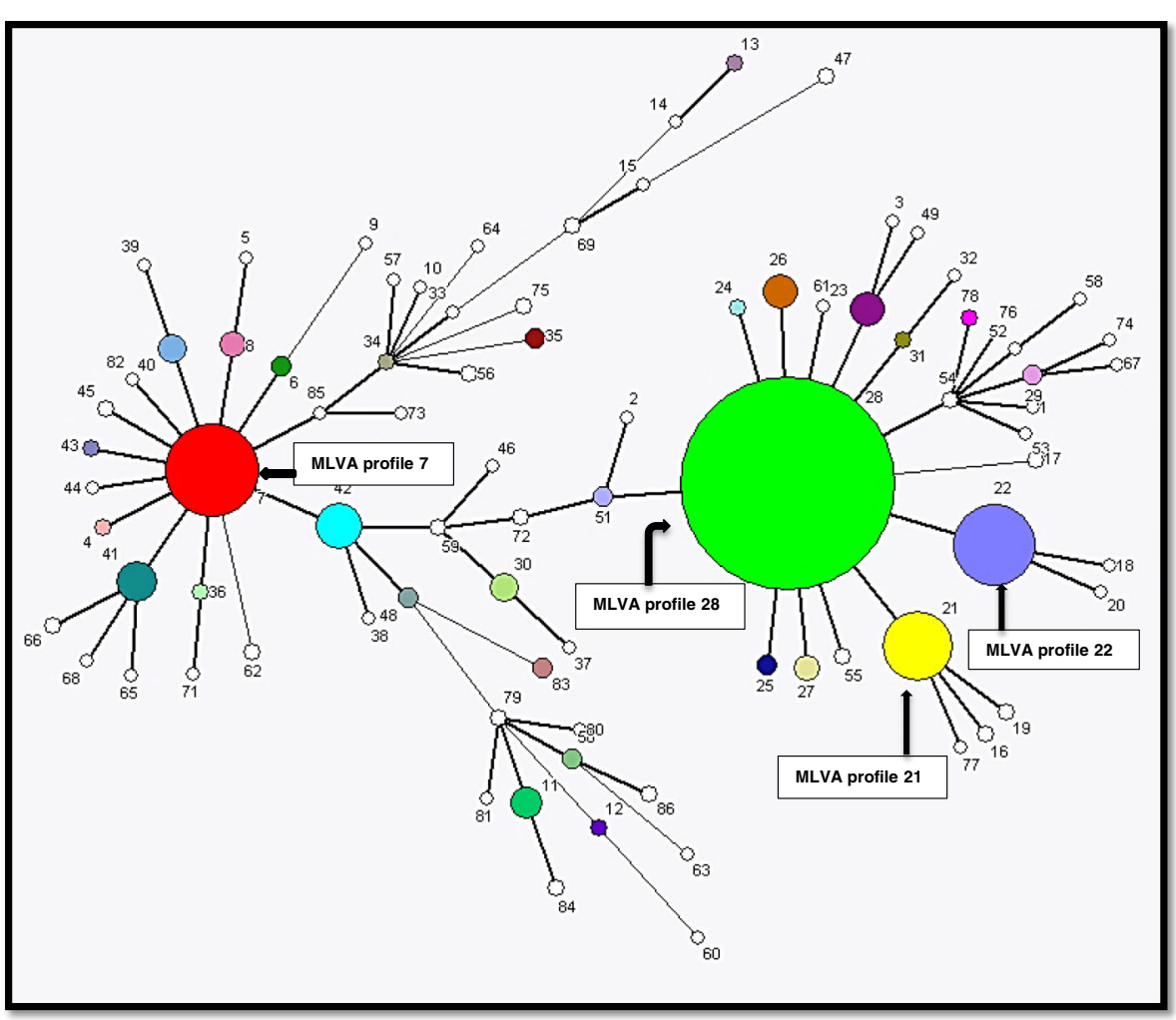

Fig. 2 MLVA MST of Salmonella Enteritidis isolates in the CED database. The circle (node) size represents the MLVA profile and the size of the node represents the number of isolates in each MLVA profile (the smaller node the fewer the number of isolates in the MLVA profile). MLVA profiles are connected by branches and the thickness of the branch indicates how many VNTR loci differences are between the connected MLVA profiles. The thick solid lines connect MLVA profiles (nodes) that differ by one VNTR locus and thin solid lines connect MLVA profiles that have two VNTR loci difference. The distance between the MLVA profiles represents the genetic divergence between two neighbouring MLVA profiles

number of alleles) within the SENTR5 locus was previously described by Malorny et al. [23], whereby SENTR5 had the second highest number of alleles in their study (10 alleles), preceded by SENTR6 (11 alleles).

In our study, SENTR5 helped show the genetic variation present within these closely related MLVA profiles. Such close relation suggests that minor changes may have occurred between these MLVA profiles and that they may have shared characteristics, which enable them to spread effectively throughout the country and cause more outbreaks, compared to other MLVA profiles. However, more outbreaks need to be analysed with MLVA, supplemented by whole genome sequencing in order to investigate such possible shared characteristics. Nonetheless a similar event has been reported previously in a study by Slinko et al., [20] on an outbreak of Salmonella Typhimurium in Brisbane Australia. Slinko et al., [20] found that outbreaks caused by the STm197 strain had produced several closely related MLVA profiles, which had caused outbreaks in many restaurants throughout the city for over two months.

Although the three MLVA profiles in our study were closely related, geographical and epidemiological analysis of the seven outbreaks does not indicate any possible links between the outbreaks. Majority of the outbreaks occurred several months apart, except for outbreak 5 (Free State Province) and outbreak 6 (Eastern Cape Province), which occurred days from each other. However, they could not be linked epidemiologically (Fig. 3).

Numerous studies have applied MLVA in the analysis of Salmonella Enteritidis in different parts of the world, and many studies have applied it in outbreak investigations [15]. However, many have remained doubtful about the stability of VNTR's during an outbreak. It is assumed that VNTR's may evolve rapidly, thereby producing multiple MLVA profiles during an outbreak [18]. Studies by Boxrud et al., [17] and Malorny et al., [23] analysed the stability of Salmonella Enteritidis VNTR's during an outbreak and found that the VNTR's had remained stable during outbreak investigations. Our current study was able to show that MLVA can be used as a molecular epidemiological tool for the investigation of outbreaks associated with Salmonella Enteritidis. MLVA was able to group all isolates from a single outbreak into a single MLVA profile; indicating the stability of the VNTR's during an outbreak. Furthermore, MLVA has faster 


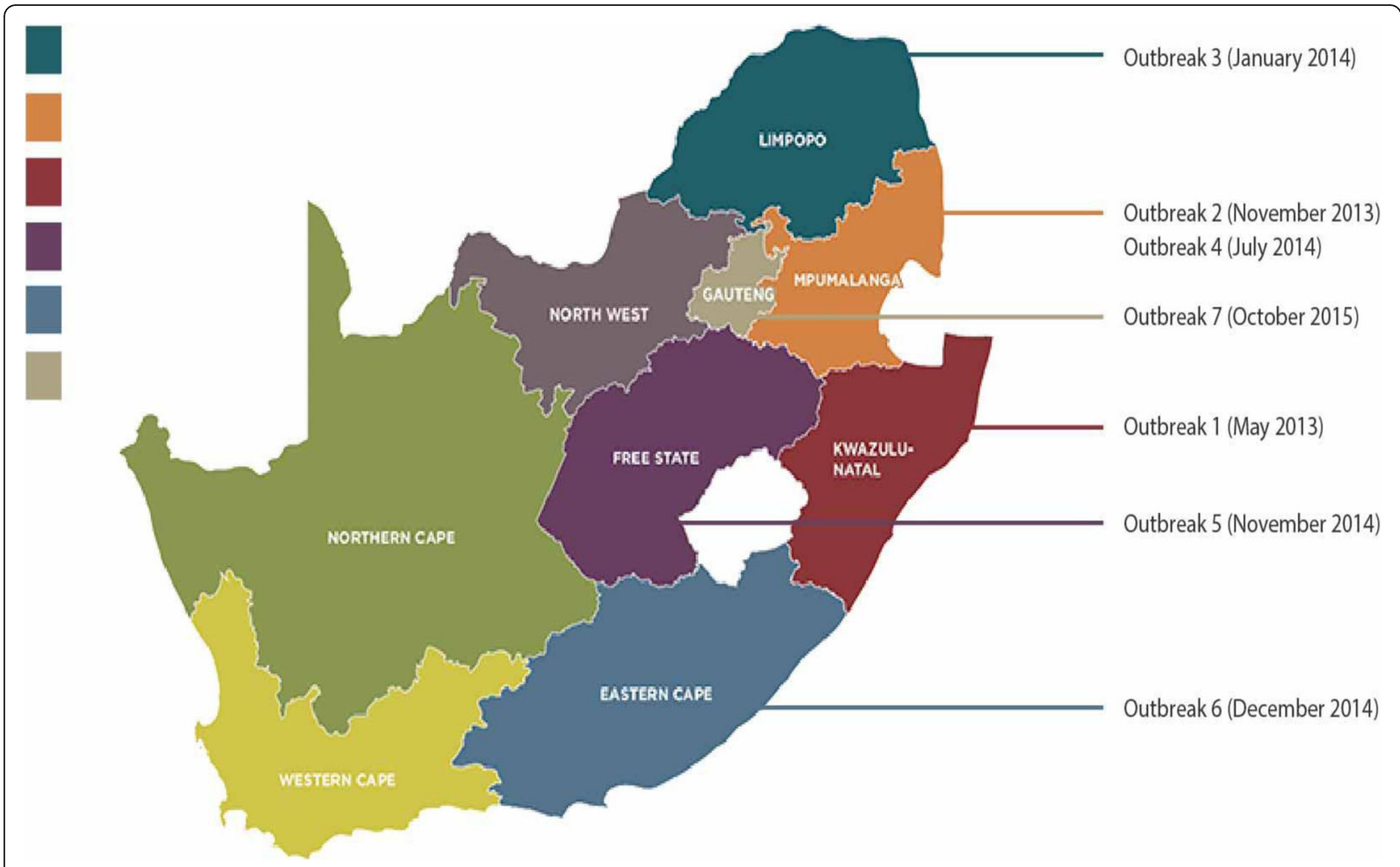

Fig. 3 South African map, illustrating the geographical regions of the seven Salmonella Enteritidis outbreaks, from the years $2013-2015$

turnaround times compared to PFGE. It is this MLVA advantage that enabled the reporting of strain relatedness results from outbreaks 5-7 (outbreaks were analysed with MLVA in real time) to the relevant personnel more quickly, thus enhancing the public health interventions.

In this study, outbreak 1_ (KZN) included an isolate from goat meat. Such a finding emphasizes the role food animals have in the spread of zoonotic pathogens (such as Salmonella Enteritidis) to the human population [24]. Therefore, it is crucial that human and animal health organisations work together to reduce pathogen transmission. More so, this also emphasizes the importance of testing food items implicated in an outbreak, in order to determine the source and cause of infection and disease.

Our study had a number of limitations. Firstly, MLVA was performed on our outbreak isolates long before the recent publication of Peters et al., [25], which described the validation of a reference/calibration set of strains for MLVA of Salmonella Enteritidis. Currently, we don't have access to this reference/calibration set of strains, as we were never invited to participate in the multi-laboratory validation study. Therefore, we were not able to normalize our MLVA data to obtain exact repeat numbers and describe MLVA profiles in the format of numbers of repeats. Therefore, currently inter-laboratory comparison of our MLVA data with other laboratories will be a challenge. Secondly, the epidemiological and clinical data of the outbreaks were not complete. This limited our ability to further analyse the link between the molecular data and epidemiological data. Lastly, all the outbreaks were foodborne related, but only two outbreaks (outbreak 1 and outbreak 3 ) had food items tested. However, results from outbreak 3 food items is unknown. This limited our ability to compare human isolates to the non-human (food) isolates.

\section{Conclusions}

In conclusion, MLVA has shown to be a reliable method for the molecular epidemiological investigation of Salmonella Enteritidis outbreaks in South Africa. Our findings emphasize the need for analysis of Salmonella Enteritidis isolates from different provinces in South Africa, in order to investigate the circulating strains (and MLVA profiles) in each province and to investigate their potential to cause outbreaks. Furthermore, this study emphasizes the importance of using the One Health approach; combining food, animal and human testing in order to curb the spread of foodborne zoonotic diseases within the country. In association with the current epidemiological surveillance programs, studies such as this can provide valuable information for the development of public health strategies to minimize or control the risk of outbreaks associated with Salmonella Enteritidis in South Africa. 


\section{Abbreviations}

CED: Centre for Enteric Diseases; EC: Eastern Cape; FS: Free State; GA: Gauteng; HAART: Highly active antiretroviral therapy; HIV: Human immunodeficiency virus; KZN: KwaZulu-Natal; LP: Limpopo; MLVA: Multi-locus variable-number tandem-repeats analysis; MP: Mpumalanga; MST: Minimum spanning tree; NICD: National Institute for Communicable Diseases; NTS: Non-typhoidal Salmonella; ORU: Outbreak Response Unit; PFGE: Pulsedfield gel electrophoresis; Salmonella Enteritidis: Salmonella enterica serovar Enteritidis; VNTR: Various variable-number tandem-repeat; WC: Western Cape

\section{Acknowledgements}

The authors would like to thank the Director of the NICD for permission to publish this article.

This work was undertaken as part of the first authors MSc. Med degree from the University of the Witwatersrand.

The authors would like to thank the GERMS-SA surveillance for the submission of isolates to the Centre for Enteric Diseases (CED). GERMS-SA members include Vanessa Quan - Lead author (vanessaq@nicd.ac.za) Ananta Nanoo, Anne von Gottberg, Andries Dreyer, Anthony Smith, Arvinda Sooka, Cecilia Miller, Charlotte Sriruttan, Cheryl Cohen, Chikwe Ihekweazu, Claire von Mollendorf, Frans Radebe, Genevie Ntshoe, Gillian Hunt, Karen Keddy, Linda de Gouveia, Linda Erasmus, Marshagne Smith, Martha Bodiba, Mbhekiseni Khumalo, Motshabi Modise, Nazir Ismail, Nelesh Govender, Nicola Page, Olga Perovic, Oliver Murangandi, Penny Crowther-Gibson, Portia Mutevedzi, Riyadh Manesen, Ruth Mpembe, Samantha Iyaloo, Sarona Lengana, Shabir Madhi, Sibongile Walaza, Sonwabo Lindani, Susan Meiring, Thejane Motladiile, Verushka Chetty (NICD); Carel Haumann, Patricia Hanise; Sandeep Vasaikar, John Black, Vanessa Pearce (Eastern Cape); Anwar Hoosen, Vicky Kleinhans (Free State); Alan Karstaedt, Caroline Maluleka, Charl Verwey, Charles Feldman, David Moore, David Spencer, Gary Reubenson, Khine Swe Swe Han, Jeannette Wadula, Jeremy Nel, Kathy Lindeque, Maphoshane Nchabeleng, Nicolette du Plessis, Norma Bosman, Ranmini Kularatne, Ruth Lekalakala, Sharona Seetharam, Theunis Avenant, Trusha Nana, Vindana Chibabhai (Gauteng); Adhil Maharj, Asmeeta Burra, Fathima Naby, Halima Dawood, Koleka Mlisana, Lisha Sookan, Praksha Ramjathan, Prasha Mahabeer, Romola Naidoo, Sumayya Haffejee, Yacoob Coovadia (Kwa-Zulu Natal); Ken Hamese, Ngoaka Sibiya (Limpopo); Greta Hoyland, Jacob Lebudi (Mpumalanga); Eunice Weenink; Riezaah Abrahams, Sindiswa Makate (Northern Cape); Ebrahim Variava, Erna du Plessis (North West); Andrew Whitelaw, Catherine Samuel, Mark Nicol, Preneshni Naicker, Shareef Abrahams (Western Cape); Adrian Brink, Elizabeth Prentice, Inge Zietsman, Maria Botha, Peter Smith, Xoliswa Poswa (AMPATH); Chetna Govind, Keshree Pillay, Suzy Budavari (LANCET); Catherine Samuel, Marthinus Senekal (PathCare); Cynthia Whitney (CDC); Keith Klugman (Emory).

\section{Funding}

This work was supported by funding from the Global Disease Detection Centre through a Cooperative Agreement (5U19GH000571-02) with the National Health Laboratory Service. Its contents are solely the responsibility of the authors and do not necessarily represent the official views of the Centers for Disease Control and Prevention.

\section{Availability of data and materials}

All data generated or analysed during this study are included in this published article.

\section{Authors' contributions}

MM did all the laboratory work and data analysis, research and construction of the manuscript. AMS was involved in the conception of the study, design of the study, guidance of manuscript preparation and reviewing of the manuscript. AMR provided information regarding the function of the ORU during outbreak investigations, construction of Table 2 and reviewing of the manuscript. KHK made substantial contributions to the conception of study, the study design, the procurement of funding, guidance of manuscript preparation and reviewing of the manuscript. All authors read and approved the final manuscript.

\section{Ethics approval and consent to participate}

Ethical clearance to do surveillance analysis has been obtained by the National Institute for Communicable Diseases (NICD), Wits protocol no: M110499 (approved 06 May 2011) and Wits protocol no: M081117 (approved 25 January 2013). In addition, a separate ethical clearance, in the name of
Munyadziwa Muvhali was obtained from the Wits Human Research Ethics Committee on the 25th of July 2014

Consent for publication

Not applicable.

Competing interests

The authors declare that they have no competing interests.

\section{Publisher's Note}

Springer Nature remains neutral with regard to jurisdictional claims in published maps and institutional affiliations.

\section{Author details}

${ }^{1}$ Centre for Enteric Diseases, National Institute for Communicable Diseases, Johannesburg, South Africa. ${ }^{2}$ Faculty of Health Sciences, University of the Witwatersrand, Johannesburg, South Africa. ${ }^{3}$ Outbreak Response Unit, Division of Public Health Surveillance and Response, National Institute for Communicable Diseases, Johannesburg, South Africa.

Received: 7 June 2017 Accepted: 19 September 2017

Published online: 02 October 2017

\section{References}

1. Bern C, Martines J, de Zoysa I, Glass RI. The magnitude of the global problem of diarrhoeal disease: a ten-year update. Bull World Health Organ. 1992;70(6):705-14.

2. Graham SM. Salmonellosis in children in developing and developed countries and populations. Curr Opin Infect Dis. 2002;15(5):507-12.

3. Kosek M, Bern C, Guerrant RL. The global burden of diarrhoeal disease, as estimated from studies published between 1992 and 2000. Bull World Health Organ. 2003;81(3):197-203.

4. Majowicz SE, Musto J, Scallan E, Angulo FJ, Kirk M, O'Brien SJ, et al. The global burden of nontyphoidal Salmonella gastroenteritis. Clin Infect Dis. 2010;50(6):882-9.

5. Rodrigue DC, Tauxe RV, Rowe B. International increase in Salmonella enteritidis: a new pandemic? Epidemiol Infect. 1990;105(1):21-7.

6. Feasey NA, Dougan G, Kingsley RA, Heyderman RS, Gordon MA. Invasive non-typhoidal Salmonella disease: an emerging and neglected tropical disease in Africa. Lancet. 2012;379(9835):2489-99.

7. Berkley JA, Lowe BS, Mwangi I, Williams T, Bauni E, Mwarumba S, et al. Bacteremia among children admitted to a rural hospital in Kenya. N Engl J Med. 2005;352(1):39-47.

8. Enwere G, Biney E, Cheung YB, Zaman SM, Okoko B, Oluwalana C, et al. Epidemiologic and clinical characteristics of community-acquired invasive bacterial infections in children aged 2-29 months in the Gambia. Pediatr Infect Dis J. 2006;25(8):700-5.

9. Morpeth SC, Ramadhani HO, Crump JA. Invasive non-typhi Salmonella disease in Africa. Clin Infect Dis. 2009;49(4):606-11.

10. Ao TT, Feasey NA, Gordon MA, Keddy KH, Angulo FJ, Crump JA. Global burden of invasive nontyphoidal Salmonella disease, 2010. Emerg Infect Dis. 2015;21(6):941-9.

11. Feasey NA, Archer BN, Heyderman RS, Sooka A, Dennis B, Gordon MA, Keddy KH. Typhoid fever and invasive nontyphoid salmonellosis, Malawi and South Africa. Emerg Infect Dis. 2010;16(9):1448-51.

12. Keddy KH, Dwarika S, Crowther P, Perovic O, Wadula J, Hoosen A, et al. Genotypic and demographic characterization of invasive isolates of Salmonella Typhimurium in HIV co-infected patients in South Africa. J Infect Dev Ctries. 2009:3(8):585-92.

13. [GERMS-SA] Group for Enteric Respiratory and Meningeal disease Surveillance in South Africa (GERMS-SA). GERMS - SA Annual Report 2012. 2012. http://www. nicd.ac.za/assets/les/2012_GERMSSA_Annual_Report.pdf. Accessed 07 Oct 2016.

14. [GERMS-SA] Group for Enteric Respiratory and Meningeal disease Surveillance in South Africa (GERMS-SA). GERMS - SA Annual Report 2013. 2013. www.nicd.ac.za/assets/files/GERMS-SA\%20AR\%202013(1).pdf. Accessed 07 Oct 2016

15. Hopkins KL, Peters TM, de Pinna E, Wain J. Standardization of multilocus variable-number of tandem-repeat analysis (MLVA) for subtyping of Salmonella enterica serovar Enteritidis. Euro Surveill. 2011;16(32):19942-52.

16. Ahmed R, Soule G, Demczuk WH, Clark C, Khakhria R, Ratnam S, et al. Epidemiologic typing of Salmonella enterica serotype Enteritidis in a 
Canada-wide outbreak of gastroenteritis due to contaminated cheese. J Clin Microbiol. 2000;38(6):2403-6.

17. Boxrud D, Pederson-Gulrud K, Wotton J, Medus C, Lyszkowicz E, Besser J, Besser J, et al. Comparison of multiple-locus variable-number tandem repeat analysis, pulsed-field gel electrophoresis and phage typing for subtype analysis of Salmonella enterica serotype Enteritidis. J Clin Microbiol. 2007:45(2):536-43.

18. Wiedmann M, Zhang W. Genomics of foodborne bacterial pathogens. New York: Springer; 2011. p. 403-6.

19. Kramer A, Kretzschmer M, Krickeberg K. Modern Infectious Disease Epidemiology; Concepts, Methods, Mathematical models and Public health. Germany: Springer; 2010. p. 125-6.

20. Slinko VG, McCall BJ, Stafford RJ, Bell RJ, Hiley LA, Sanderg SM, et al. Outbreaks of Salmonella Typhimurium page type 197 of multiple genotypes linked to an egg producer. Commun Dis Intell Q Rep. 2009;33(4):419-25.

21. DPHSR, ORU, NICD-NHLS. NICD-NHLS handbook for diagnosis of foodborne illness clusters / outbreaks. 2nd ed; 2016. http://nicd.ac.za/assets/files/NICDNHLS\%20Handbook\%20for\%20Diagnosis\%20of\%20Foodborne\%20illness\% 200utbreaks_2016.pdf. Accessed 14 Nov 2016

22. Grimont AD, Weill FX. Antigenic formulae of the Salmonella serovars. WHO Centre for Reference and Research on Salmonella. Institute Pasteur. France. 9 2007. http://www.pasteur.fr/ip/portal/action/WebdriveActionEvent/oid/ 01s-000036-089. Accessed 24 Nov 2016.

23. Malorny B, Junker E, Helmuth R. Multi-locus variable-number tandem repeat analysis for outbreak studies of Salmonella enterica serotype Enteritidis. BMC Microbiol. 2008. doi:10.1186/1471-2180-8-84.

24. Gal-Mor O, Boyle EC, Grassl GA. Same species, different diseases, how and why typhoidal and non-typhoidal Salmonella enterica serovars differ. Front Microbiol. 2014. doi:10.3389/fmicb.2014.00391.

25. Peters T, Bertrand S, Björkman JT, Brandal LT, Brown DJ, Erdõsi T, et al. Multi-laboratory validation study of multilocus variable-number tandem repeat analysis (MLVA) for Salmonella enterica serovar Enteritidis, 2015. Euro Surveill. 2007;22(9):30477. doi:10.2807/1560-7917.ES.2017.22.9.30477.

\section{Submit your next manuscript to BioMed Central and we will help you at every step:}

- We accept pre-submission inquiries

- Our selector tool helps you to find the most relevant journal

- We provide round the clock customer support

- Convenient online submission

- Thorough peer review

- Inclusion in PubMed and all major indexing services

- Maximum visibility for your research

Submit your manuscript at www.biomedcentral.com/submit

) Biomed Central 